\title{
CdTe semiconductor nanowires and NiFe ferro-magnetic metal nanowires electrodeposited into cylindrical nano-pores on the surface of anodized aluminum
}

\author{
TAKESHI OHGAI ${ }^{1,2, *}$, LAURENT GRAVIER ${ }^{1}$, XAVIER HOFFER $^{1}$ and JEAN-PHILIPPE ANSERMET ${ }^{1}$ \\ ${ }^{1}$ Institut de Physique des Nanostructures, Ecole Polytechnique Fédérale de Lausanne, CH-1015, Lausanne-EPFL, \\ Switzerland \\ ${ }^{2}$ Department of Materials Science and Engineering, Nagasaki University, Bunkyo-machi 1-14, Nagasaki, 852-8521, \\ Japan \\ (*author for correspondence, e-mail: ohgai@net.nagasaki-u.ac.jp; phone: +81-95-819-2638; fax: +81-95-819-2638)
}

Received 16 June 04; accepted in revised form 15 December 04

Key words: CdTe, electrodeposition, magnetoresistance, nanowire, NiFe, semiconductor

\begin{abstract}
Cylindrical nano-pores of an anodized aluminum oxide layer on the surface of bulk aluminum were used as templates for the electrochemical growth of semiconductor and magnetic nanowires. The electrodeposition of CdTe and $\mathrm{NiFe}$ was investigated to determine the optimum conditions for each nanowire growth over a wide range of cathode potentials. The desired composition of $\mathrm{Cd}_{50} \mathrm{Te}_{50}$ and $\mathrm{Ni}_{80} \mathrm{Fe}_{20}$ was achieved by controlling the cathode potential during electrodeposition. Temperature dependences of resistance for CdTe nanowires confirmed the semiconductor character with amorphous behavior at low temperature, while those of NiFe nanowires showed metallic character. The anisotropic magnetoresistance (AMR) of NiFe nanowires reached $1.9 \%$ at $300 \mathrm{~K}$.
\end{abstract}

\section{Introduction}

Electron transport properties of nanowires have received much attention due to novel physical phenomena and applications for electronic materials. Recently, several studies have been reported on magnetic or semiconductor nanowires electrodeposited into nanoporous templates [1-6] for the purpose of magnetic sensors, memory cells, photovoltaics, light emission diodes (LED), and other applications. Using commercially available ion-track etched polycarbonate membrane filters or anodized aluminum oxide membrane filters, $\mathrm{Bi}_{2} \mathrm{Te}_{3}[4], \mathrm{CdTe}$ [5] and PbSe [6] semiconductor nanowires or $\mathrm{Co} / \mathrm{Cu}$ [7-9], $\mathrm{NiFe} / \mathrm{Cu}$ [10] and $\mathrm{CoNiCu} /$ $\mathrm{Cu}$ [11] multilayered magnetic nanowires have been synthesized and characterized. Recently, Zenger et al. reported the electrodeposition of $\mathrm{NiFe}$ and $\mathrm{Fe}$ nanopillars using a PMMA template synthesis technique [12]. In this report, the single domain character of a $\mathrm{NiFe}$ nanopillar has been demonstrated. The electrochemical growth of these nanowires started from a conductive metallic layer such as $\mathrm{Au}$ or $\mathrm{Cu}$ sputtered on one side of the membrane.

Using anodized aluminum oxide pores on the surface of bulk aluminum, CdS semiconductor nanowires [13] or $\mathrm{Ni}, \mathrm{Co}$ and $\mathrm{Fe}$ magnetic nanowires [14-18] have also been synthesized and characterized. Electrodeposition of nanowires into the anodized aluminum oxide pores can be carried out if an alternating current is applied to reduce the charging effect of the barrier layer at the pore bottom [19]. For the investigation of electron transport properties of nanowires, this resistive barrier layer should be removed to achieve good electrical contacts at the pore bottom. It is well known that the barrier layer can be removed from the substrate side direction by dissolving the massive metallic aluminum backing [20-22]. However, since the thickness of barrier layer is assumed to be around several tens of nm [23], this layer can be removed or thinned using a chemical etching technique from the pore side without dissolving the aluminum substrate [24-26].

Aluminum has been conventionally used in the field of civil architecture as well as microelectronics. As construction and building materials, aluminum shows excellent physical and chemical properties such as lightweight, mechanical strength and corrosion resistance. As an interconnect metal and wiring material, aluminum is applied in an ultra large scale integration (ULSI) processing. If anodization of aluminum and electrodeposition of semiconductor (SEMI) or magnetic (MAG) nanowires can be directly applied to the pores of aluminum surfaces, the template synthesis technique will be a most promising candidate not only in the massproduction of solar cell panels, LED display, hybrid 


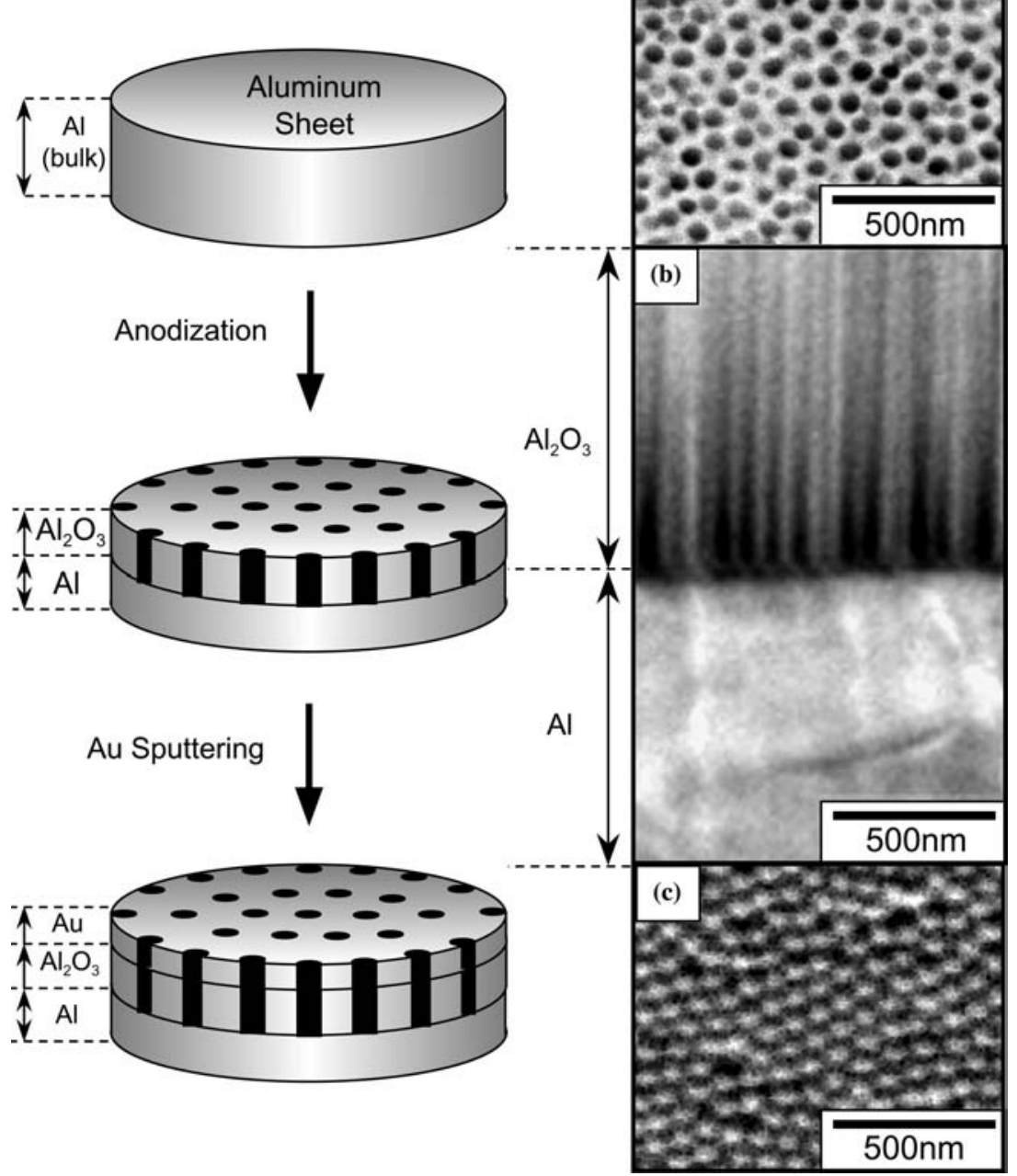

Fig. 1. Fabrication process of anodized aluminum template (left-side). SEM images of pore top plane (a), cross sectional view (b) and pore bottom plane (c) of anodized aluminum template. The anodized aluminum oxide layer has a typical porous columnar structure and the porelength is approximately $2000 \mathrm{~nm}$. The pore-diameter is approximately $60 \mathrm{~nm}$.

ULSI, etc., but also in the fundamental study of magnetic semiconductors such as MAG/SEMI multilayered or MAG-SEMI alloy type (NiFeCdTe, $\mathrm{CoCdTe}$, etc.) novel nanowires.

In this study, we report the fabrication of templates with cylindrical nano-pores using an anodized aluminum oxide layer at the surface of bulk aluminum. CdTe semiconductor nanowires and $\mathrm{NiFe}$ ferromagnetic nanowires were electrodeposited into the nano-porous templates and the temperature dependence of resistance was examined to investigate the electron transport properties of the nanowires. Mott-Davis plots on CdTe nanowires and anisotropic magnetoresistance (AMR) on $\mathrm{NiFe}$ nanowires were also investigated.

\section{Experimental procedure}

\subsection{Template synthesis}

Figure 1 (left-side) shows the fabrication process of anodized aluminum templates. Commercially available aluminum sheets (thickness: $0.5 \mathrm{~mm}$ ) were used as a starting material to prepare anodized aluminum templates. First, the aluminum sheets were electrochemically polished in a solution of ethanol and perchloric acid ( $75 \mathrm{vol} . \%$ of ethanol, $25 \mathrm{vol} . \%$ of perchloric acid) to achieve a mirror-like surface. During the electrochemical polishing, the cell voltage was kept at $8 \mathrm{~V}$ for $10 \mathrm{~min}$. Then, the polished aluminum sheets were anodized in an aqueous solution containing $0.3 \mathrm{~mol} \mathrm{l}^{-1}$ oxalic acid to obtain a nano-porous aluminum oxide layer on the surface. The cell voltage was kept at $50 \mathrm{~V}$ for 10 min during anodization.

Figure 1 (right-side) shows the SEM images of a pore top planar view (Figure 1(a)), a cross-sectional view (Figure 1(b)) and a pore bottom back side view (Figure 1(c)) of an anodized aluminum template. For the observation of pore bottom back side (barrier layer), the massive metallic aluminum substrate was dissolved in hydrochloric acid containing small amount of cupric ions $\left(1.6 \mathrm{~g} \mathrm{l}^{-1} \mathrm{CuSO}_{4} \cdot 5 \mathrm{H}_{2} \mathrm{O}\right)$. The pore diameter is approximately $60 \mathrm{~nm}$ and the pore density is of the order of $10^{10}$ pores $\mathrm{cm}^{-2}$ as shown in 
Figure 1(a), while the oxide layer had a typical porous columnar structure (Figure 1(b)) and the pore length was approximately $2000 \mathrm{~nm}$. The existence of a barrier layer is made obvious by looking at the pore bottom of the anodized aluminum oxide layer (Figure 1(c)). To remove or thin this barrier layer without dissolving the metallic aluminum backing, the anodized aluminum templates were subsequently immersed in an aqueous solution containing 5 vol. $\%$ of phosphoric acid for $50 \mathrm{~min}$ prior to the electrodeposition process. For the electrodeposition of CdTe into the anodized aluminum templates, a small amount of $\mathrm{Cu}$ (around $10 \mathrm{~nm}$ thickness) was electrodeposited at the pore bottom to assist the electrical contact of CdTe with the aluminum substrate. A thin gold layer (thickness: $50 \mathrm{~nm}$ ), which serves as an in-situ electrical contact [27] for the grown $\mathrm{NiFe}$ nanowires, was sputtered on the surface of the templates. This layer was thin enough to leave the pores open. For the electrical contact of CdTe nanowires, the thin gold contact layer was sputtered after the electrodeposition of CdTe to make parallel contacts with multiple nanowires.

\subsection{Nanowire growth and resistance measurement}

For the electrodeposition of $\mathrm{CdTe}$ and $\mathrm{NiFe}$ nanowires into the anodized aluminum templates, electrolytic solutions were prepared with ion-exchanged water containing the following chemicals. CdTe Bath: $3 \mathrm{CdSO}_{4} \cdot 8 \mathrm{H}_{2} \mathrm{O} \quad 25.6 \mathrm{~g} \mathrm{l}^{-1}\left(\mathrm{Cd}^{2+}: 0.1 \mathrm{~mol} \mathrm{l}^{-1}\right), \quad \mathrm{TeO}_{2}$ $1.6 \mathrm{~g} \mathrm{l}^{-1} \quad\left(0.01 \mathrm{~mol} \mathrm{l}^{-1}\right)$, and $\mathrm{H}_{2} \mathrm{SO}_{4} \quad 98 \mathrm{~g}^{-1}$ $\left(1.0 \mathrm{~mol} \mathrm{l}^{-1}\right) . \quad \mathrm{NiFe} \quad$ Bath: $\mathrm{NiSO}_{4} \cdot 6 \mathrm{H}_{2} \mathrm{O} \quad 120 \mathrm{~g} \mathrm{l}^{-1}$ $\left(0.457 \mathrm{~mol} \mathrm{l}^{-1}\right), \mathrm{FeSO}_{4} \cdot 7 \mathrm{H}_{2} \mathrm{O} 6.0 \mathrm{~g} \mathrm{l}^{-1}\left(0.0215 \mathrm{~mol} \mathrm{l}^{-1}\right)$, and $\mathrm{H}_{3} \mathrm{BO}_{3} 45 \mathrm{~g} \mathrm{l}^{-1}\left(0.728 \mathrm{~mol} \mathrm{l}^{-1}\right)$. Cathodic polarization curves were measured over a wide potential range to determine the optimum conditions for CdTe and $\mathrm{NiFe}$ deposition. The nanowires were electrodeposited potentio-statically at the optimized potentials using a PC-controlled potentiostat and the composition of each deposit was determined using an EDX analyzer.

The temperature dependence of the resistance on each nanowire was measured in the range from 10 to $300 \mathrm{~K}$ using a cold-finger cryostat system. The magnetoresistance of NiFe nanowires was measured at $300 \mathrm{~K}$ using a lock-in amplifier detection system, applying a $1 \mu \mathrm{A}$ current and sweeping the applied magnetic field slowly up to $10 \mathrm{kOe}$.

\section{Results and discussion}

\subsection{Electrodeposition of nanowires into nano-porous templates}

Figure 2(a) shows a cathodic polarization curve of an anodized aluminum template in the solution containing $\mathrm{Cd}^{2+}$ and $\mathrm{HTeO}_{2}^{+}$ions (CdTe Bath). The equilibrium potentials of $\mathrm{Te}\left(E_{\mathrm{Te}}^{\mathrm{eq}}\right)$, CdTe $\left(E^{\mathrm{eq}} \mathrm{CdTe}\right)$ and $\mathrm{Cd}\left(E^{\mathrm{eq}} \mathrm{Cd}\right)$ are estimated to be around $+0.32,-0.12$ and $-0.63 \mathrm{~V}$ (vs $\mathrm{Ag} / \mathrm{AgCl}$ ) based on the following electrochemical reactions.

$$
\begin{aligned}
& \mathrm{HTeO}_{2}^{+}+3 \mathrm{H}^{+}+4 \mathrm{e}^{-}=\mathrm{Te}+2 \mathrm{H}_{2} \mathrm{O} \\
& \mathrm{Cd}^{2+}+\mathrm{Te}+2 \mathrm{e}^{-}=\mathrm{CdTe} \\
& \mathrm{Cd}^{2+}+2 \mathrm{e}^{-}=\mathrm{Cd}
\end{aligned}
$$

As shown in this figure, the cathodic current occurs and increases at around $0 \mathrm{~V}$ and this current seems to correspond to the electrodeposition of Te (Equation 1) and CdTe (Equation 2). Recently, Gonzalez et al. reported the electrodeposition of $\mathrm{Bi}_{2} \mathrm{Te}_{3}$ [28]. Based on their cyclic voltammetric study, the deposition potentials of $\mathrm{Te}$ and $\mathrm{Bi}_{2} \mathrm{Te}_{3}$ were determined to be less-noble than 0.19 and $0.05 \mathrm{~V}$. Also, Takahashi et al. reported the electrodeposition of CdTe with Cu-doping [29]. According to their cathodic voltammogramic study, the deposition potentials of $\mathrm{Te}$ and $\mathrm{CdTe}$ were determined to be less-noble than 0.07 and $0.20 \mathrm{~V}$. These results are in good agreement with those of this study. With
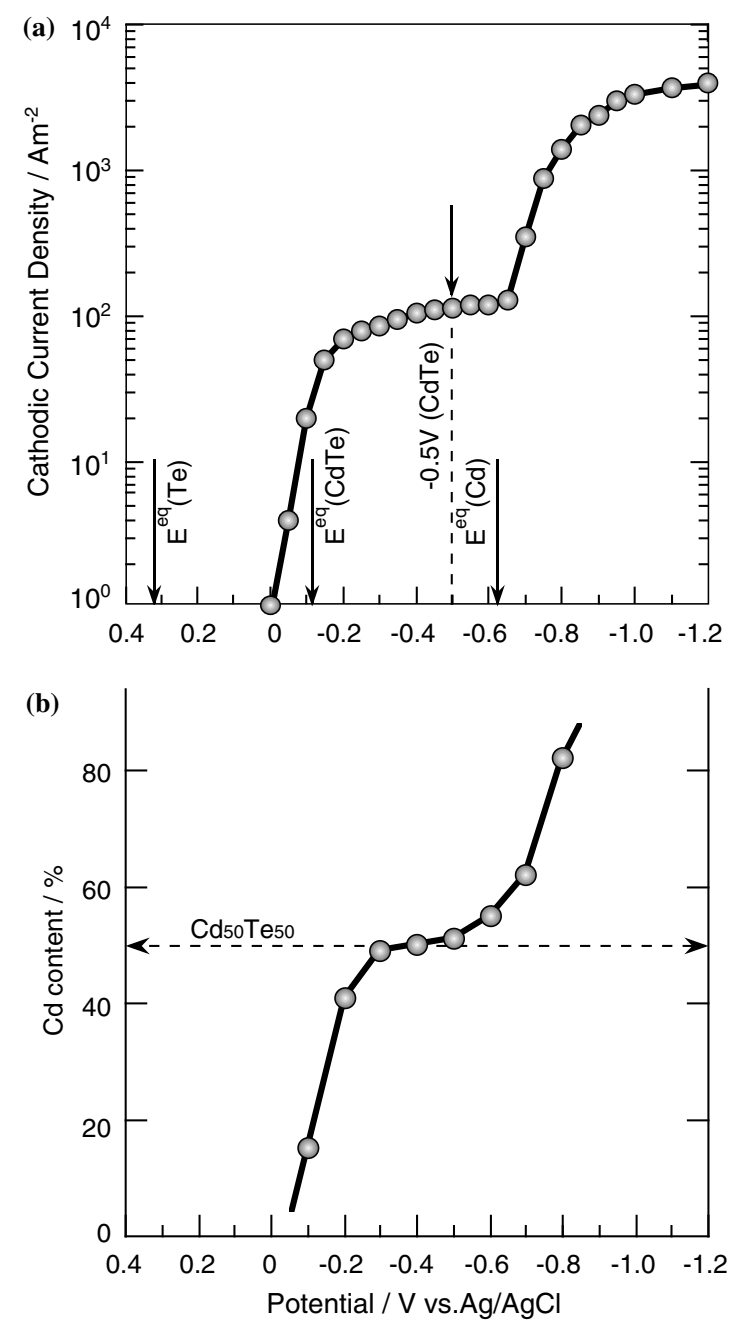

Fig. 2. Cathodic polarization curve of anodized aluminum templates in a solution containing $\mathrm{HTeO}_{2}^{+}$ions and $\mathrm{Cd}^{2+}$ ions (a). Cd-content in deposits obtained at various cathode potentials (b). 
increasing cathodic current, at around $100 \mathrm{~A} \mathrm{~m}^{-2}$, the potential shifts in the less-noble direction. This phenomenon can be explained by the formation of a resistive semiconductor phase (Equation 2) and the diffusion control of $\mathrm{HTeO}_{2}^{+}$ions. In the potential region close to $E^{\mathrm{eq}} \mathrm{Cd}$, the cathodic current increases again at around $-0.6 \mathrm{~V}$. It is well known that $\mathrm{Cd}^{2+}$ ions begin to electrodeposit without an accompanying overpotential from the aqua ions. In the sulfuric acid aqueous solution used in this study, $\mathrm{Cd}^{2+}$ ions exist as simple aqua ions. Therefore, this increase in cathodic current corresponds to the electrodeposition of $\mathrm{Cd}$ (Equation 3).

Figure 2(b) shows Cd-content in the deposits obtained at various cathode potentials. The Cd-content increases with increasing cathode potential and, at potentials more noble than $-0.3 \mathrm{~V}$, Te-rich deposits are obtained, while Cd-rich deposits are obtained at potentials less noble than $-0.5 \mathrm{~V}$. In the potential range from -0.3 to $-0.5 \mathrm{~V}$, a stoichiometric composition (1:1) of CdTe deposits is realized. It is well known that the codeposition of $\mathrm{Cd}$ with $\mathrm{Te}$ proceeds based on the underpotential deposition of $\mathrm{Cd}[30]$ and the results obtained in this study can also be explained on the basis of the induced codeposition mechanism reported by Kröger [31].

Figure 3(a) shows the polarization curves of mixed solution containing $\mathrm{Ni}^{2+}$ ions and $\mathrm{Fe}^{2+}$ ions $(\mathrm{NiFe}$ Bath; black line) and single solution containing $0.457 \mathrm{~mol} \mathrm{l}^{-1}$ of $\mathrm{Ni}^{2+}$ ions (grey line). The equilibrium potentials of $\mathrm{Ni}$ $\left(E^{\mathrm{eq}} \mathrm{Ni}\right)$ and $\mathrm{Fe}\left(E^{\mathrm{eq}} \mathrm{Fe}\right)$ are estimated to be around -0.46 and $-0.64 \mathrm{~V}$ (vs $\mathrm{Ag} / \mathrm{AgCl}$ ) based on the following electrochemical reactions.

$$
\begin{aligned}
& \mathrm{Ni}^{2+}+2 \mathrm{e}^{-}=\mathrm{Ni} \\
& \mathrm{Fe}^{2+}+2 \mathrm{e}^{-}=\mathrm{Fe}
\end{aligned}
$$

In the Ni single solution, cathodic current occurs at around $-0.1 \mathrm{~V}$, which is more noble than $E_{\mathrm{Ni}}^{\mathrm{eq}}$. This current is considered to be due to hydrogen evolution at the cathode. With increasing cathodic current, the cathode potential shifts in the less noble direction due to diffusion control by hydrogen ion transport. At potentials less noble than $E^{\mathrm{eq}} \mathrm{Ni}$, the cathodic current again increases at around $-0.6 \mathrm{~V}$. Iron-group metals such as $\mathrm{Ni}$, Co and Fe electrodeposit accompanied by a significant overpotential even in an aqueous solution $[32,33]$. Therefore, this increase in cathodic current is considered to be due to deposition of $\mathrm{Ni}$. On the other hand, in $\mathrm{Ni}$ and $\mathrm{Fe}$ mixed solution (NiFe Bath), the deposition of $\mathrm{Ni}$ occurs at around $-0.8 \mathrm{~V}$, which is less noble than in Ni single solution. It is well known that $\mathrm{Ni}$ deposition is suppressed by the existence of $\mathrm{Fe}^{2+}$ ions and the less noble $\mathrm{Fe}$ preferentially deposits [34]. Therefore, the polarization of $\mathrm{Ni}$ deposition due to $\mathrm{Fe}^{2+}$ ions, which is observed in this study, can be explained by the anomalous codeposition mechanism reported by Dahms et al. [34].
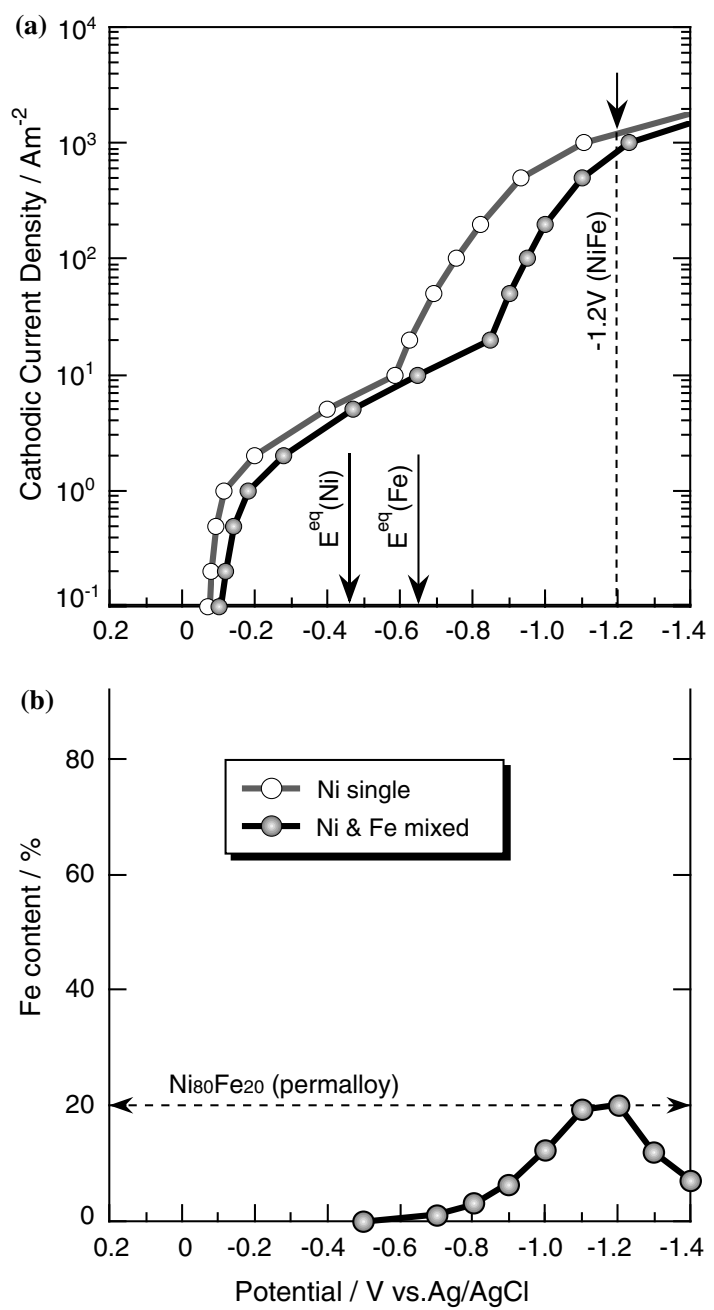

Fig. 3. Cathodic polarization curves of anodized aluminum templates in a solution containing $\mathrm{Ni}^{2+}$ ions and $\mathrm{Fe}^{2+}$ ions (a). Fe-content in deposits obtained at various cathode potentials (b).

Figure 3(b) shows Fe-content in the deposits obtained at various cathode potentials. The Fe-content increases with increasing cathode potential up to -1.1 to $-1.2 \mathrm{~V}$, and in the potential region less noble than $-1.2 \mathrm{~V}, \mathrm{Fe}-$ content decreases with increasing cathode potential. This decrease in Fe-content is caused by diffusion control by $\mathrm{Fe}^{2+}$ ions. In the potential range from -1.1 to $-1.2 \mathrm{~V}$, permalloy composition $\left(\mathrm{Ni}_{80} \mathrm{Fe}_{20}\right)$ of $\mathrm{NiFe}$ deposits can be realized.

Based on the polarization curves and the composition analysis of nanowires obtained in this study, the optimum conditions for $\mathrm{Cd}_{50} \mathrm{Te}_{50}$ nanowire growth are determined to be around -0.3 to $-0.5 \mathrm{~V}$, that is, at potentials more noble than $E^{\text {eq }} \mathrm{Cd}$ to avoid the codeposition of metallic $\mathrm{Cd}$ with $\mathrm{CdTe}$. The optimum condition for $\mathrm{Ni}_{80} \mathrm{Fe}_{20}$ nanowire growth is determined to be around -1.1 to $-1.2 \mathrm{~V}$, that is, at potentials more noble than the diffusion controlled region of $\mathrm{Ni}^{2+}$ and $\mathrm{Fe}^{2+}$ ions.

Figure 4 shows SEM images of CdTe nanowires (a) and $\mathrm{NiFe}$ nanowires (b) separated from the nano-porous anodized aluminum oxide layer. The nano-porous 


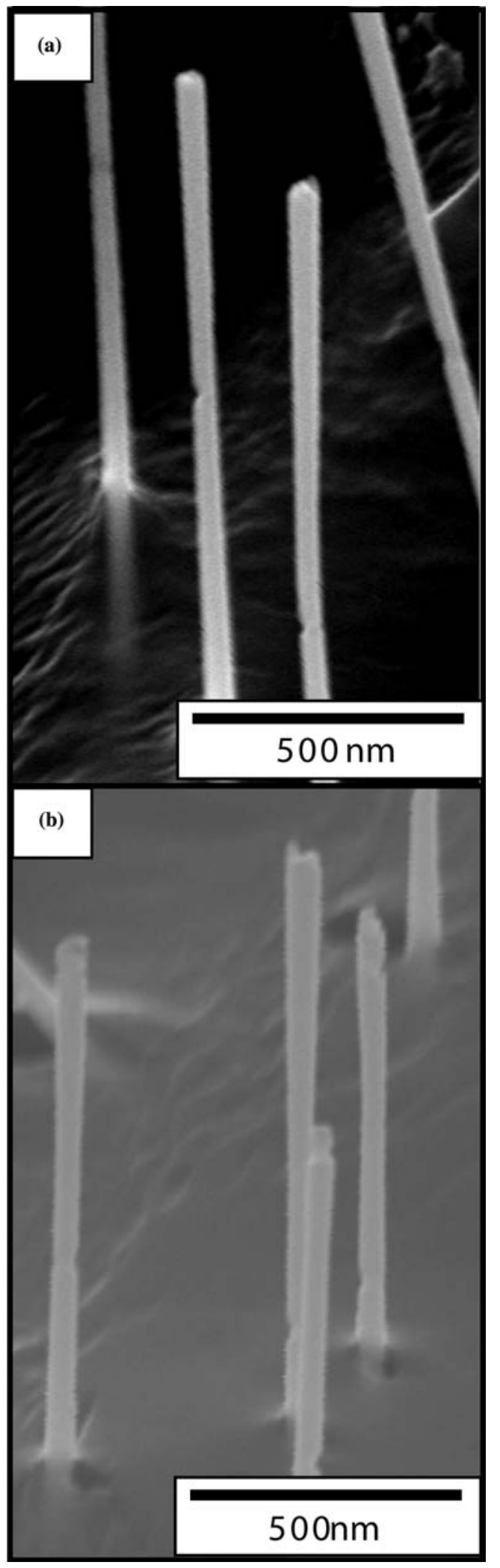

Fig. 4. SEM images of CdTe nanowires (a) and NiFe nanowires (b) separated from the nano-porous anodized aluminum oxide layer.

template was dissolved in $5 \mathrm{~N}-\mathrm{NaOH}$ solution to the observe the $\mathrm{CdTe}$ and $\mathrm{NiFe}$ nanowires. As shown in these images, the nanowires have cylindrical shape with a large aspect ratio, and the diameter and length correspond well to those of the nano-porous template.

\subsection{Electron transport properties of $\mathrm{CdTe}$ and NiFe nanowires}

Figure 5(a) shows the temperature dependence of resistance of CdTe nanowires electrodeposited at $-0.5 \mathrm{~V}$. The resistance of CdTe nanowires shows an exponential increase with decreasing temperature, indicating their semiconductor character. When the nanowires were electrodeposited at less noble potentials than $-0.5 \mathrm{~V}$, for example at -0.6 and $-0.7 \mathrm{~V}$, the increase in resistance in the low temperature region was not so remarkable as that obtained at $-0.5 \mathrm{~V}$, due to the excess co-deposited metallic $\mathrm{Cd}$. The activation energy $E_{\mathrm{a}}$ was determined, using the usual relation for the conductivity $\sigma$ in semiconductors:

$$
\sigma=\sigma_{0} \exp \left(-E_{\mathrm{a}} / k T\right)
$$

$E_{\mathrm{a}}$ is not constant over the temperature range. The maximum value found at room temperature is $19 \mathrm{meV}$ for an electrodeposition potential of $-0.5 \mathrm{~V}$ and this

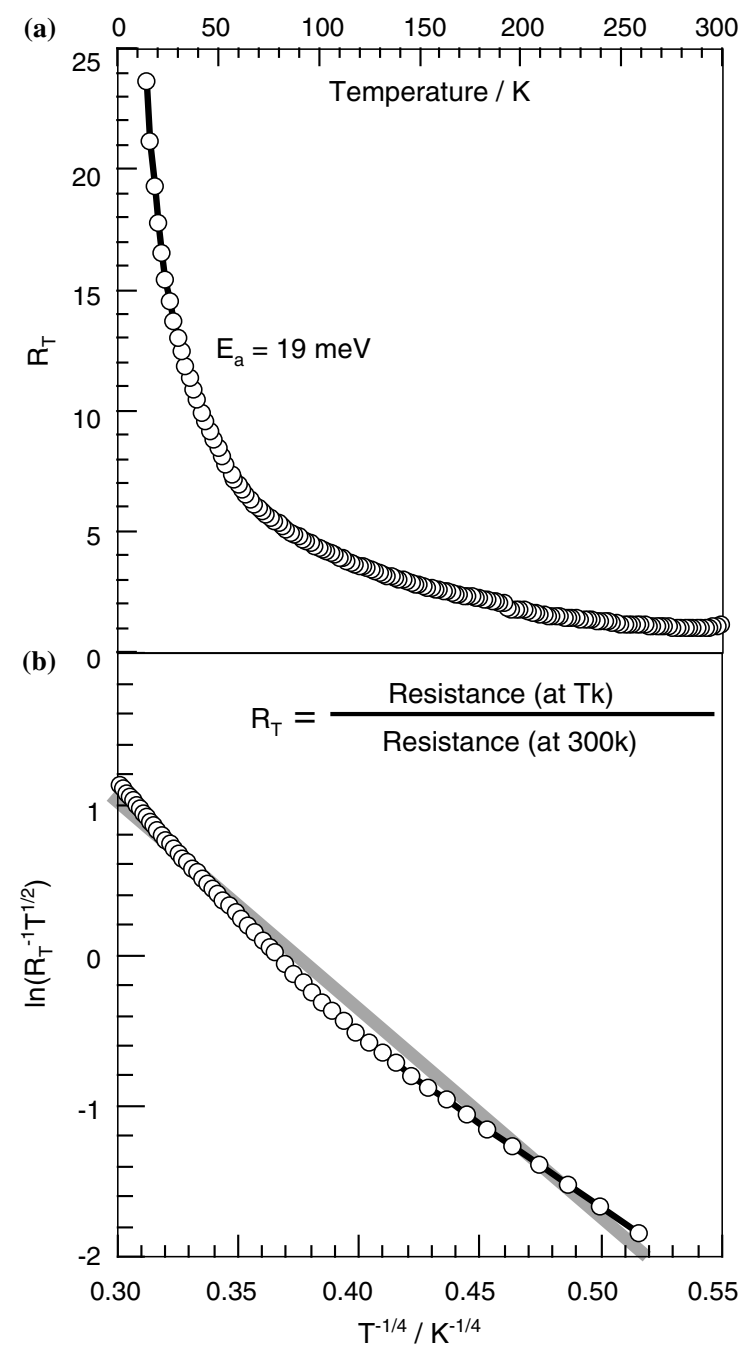

Fig. 5. Temperature dependence of resistance at $10-300 \mathrm{~K}$ (a) and Mott-Davis plots at low temperatures (14-120 K) (b) for CdTe nanowires electrodeposited at $-0.5 \mathrm{~V}$. 


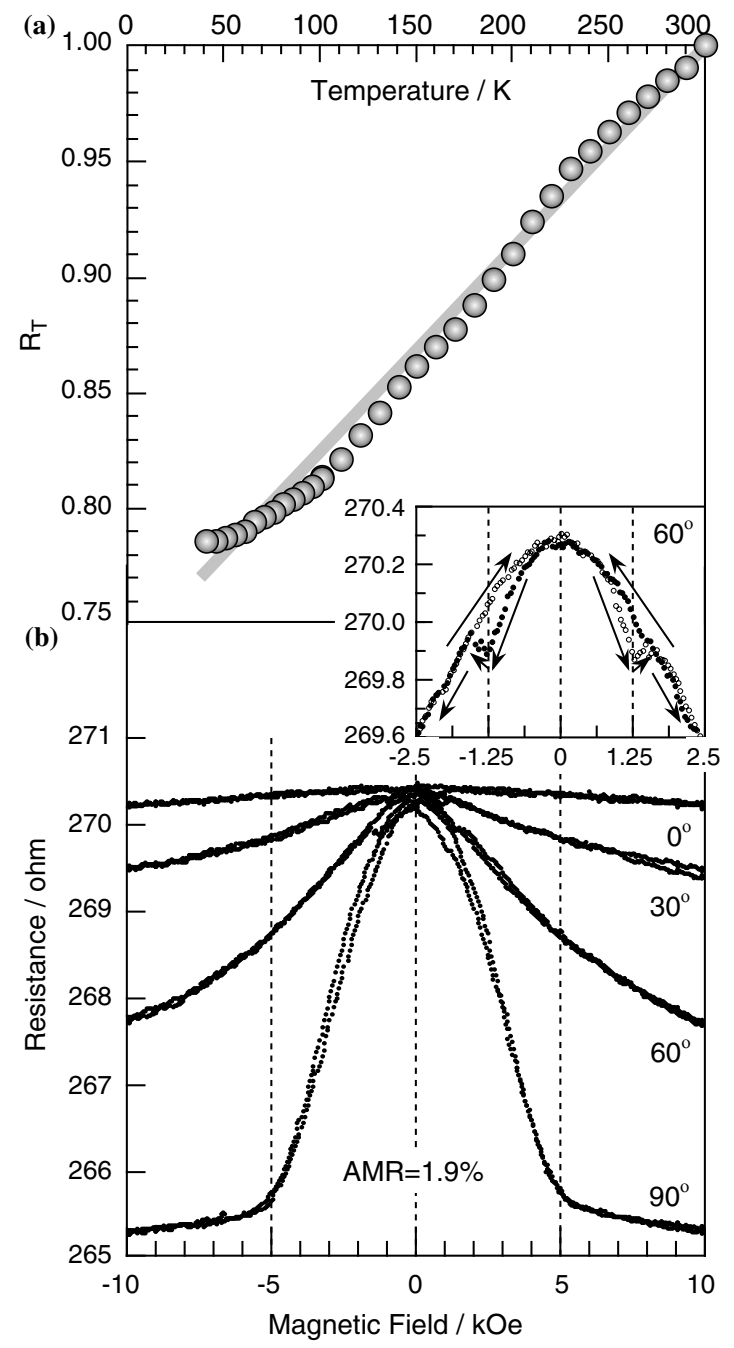

Fig. 6. Temperature dependence of resistance (a) and magnetoresistive hysteresis (b) on $\mathrm{NiFe}$ nanowires electrodeposited at $-1.2 \mathrm{~V}$. (Inset-figure shows the close-up data of AMR hysteresis measured at $\left.60^{\circ}\right)$

value is far from the bandgap energy of CdTe crystals $\left(E_{\mathrm{g}}^{\mathrm{CdTe}}=1.44 \mathrm{eV}\right)$. It is well known that impurity elements and crystal defects in a semiconductor induce a localized state in the bandgap. In this case, the bandgap energy of quasi-semiconductor materials could be several tens of $\mathrm{meV}[35,36]$.

To examine a detail of electron transport property of the electrodeposited CdTe nanowires, the temperature dependence of the resistance at low temperature (14 $120 \mathrm{~K}$ ) is analyzed with respect to the Mott-Davis model [37].

$$
\sigma=\sigma_{0} T^{-1 / 2} \exp \left(-B T^{-1 / 4}\right)
$$

As shown in figure 5(b), the experimental data is well fitted by the Mott-Davis plot at low temperature. This suggests that the electrodeposited CdTe nanowires are composed from amorphous phase and the electron transport is based on a hopping conduction mechanism $[38,39]$.
Figure 6(a) shows the temperature dependence of resistance on $\mathrm{NiFe}$ nanowires electrodeposited at $-1.2 \mathrm{~V}$. The resistance of $\mathrm{NiFe}$ nanowires decreases linearly with decreasing temperature and this temperature dependence confirms that the sample has a typical metallic character. Figure 6(b) shows magnetoresistance curves of $\mathrm{NiFe}$ nanowires electrodeposited at $-1.2 \mathrm{~V}$. Here, MR ratio was defined as.

$$
\mathrm{MR} \text { ratio }=100\left(R_{\max }-R_{\min }\right) R_{\min }^{-1}
$$

The resistance of $\mathrm{NiFe}$ nanowires strongly depends on the magnetic field direction and the AMR reaches up to $1.9 \%$ at $90^{\circ}$ (perpendicular magnetic field to the wire axis). The saturating field is estimated to be around $5 \mathrm{kOe}$, which is smaller than that of typical Ni nanowires. The inset-figure shows the close-up data for a AMR hysteresis curve of a $\mathrm{NiFe}$ nanowire measured at $60^{\circ}$. In this figure, a resistance jump was observed at $1.25 \mathrm{kOe}$ with increasing magnetic field. This phenomenon confirms that a single nanowire is electrically contacted with the anodized aluminum template. According to the experimental results obtained in this study, it is confirmed that the pore bottom treatment technique using phosphoric acid is quite effective in removing most or all of the barrier layer and in making good metallic electrical contact between the aluminum substrate and electrodeposited nanowires.

\section{Conclusion}

CdTe and $\mathrm{NiFe}$ nanowires were fabricated on the surface of anodized aluminum using anodization and electrodeposition techniques. According to the temperature dependence of the resistance, CdTe nanowires clearly show semiconductor characteristics. Mott-Davis plots at low temperature suggest that the electrodeposited CdTe nanowires are composed from amorphous phase and the electron transport is based on a hopping conduction mechanism. NiFe nanowires showed clear metallic characteristics on the temperature dependence of the resistance. About $1.9 \%$ of AMR response for a $\mathrm{NiFe}$ single nanowire was successfully observed in anodized aluminum templates.

\section{Acknowledgements}

This work was supported in part by the Swiss Commission for Technology and Innovation (CTI) through the Technology Oriented Program - Nanometer in the 21st Century, TOP-NANO21 (Contract CTI No. 5812.1 TNS) and the European Commission (EC) through the Human Potential Program - Research Training Network (HPRN), European Network on Ion Track Technology, EuNITT (Contract No. HPRN-CT-2000-00047). 


\section{References}

1. C.R. Martin, Adv. Mater. 3 (1991) 457.

2. D. Aimawlawi, N. Coombs and M. Moskovits, J. Appl. Phys. 70 (1991) 4421.

3. T.M. Whitney, J.S. Jiang, P.C. Searson and C.L. Chien, Science. 261 (1993) 1316.

4. A.L. Prieto, M.S. Sander, M.S. Martin-Gonzalez, R. Gronsky, T. Sands and A.M. Stacy, J. Am. Chem. Soc. 123 (2001) 7160.

5. D. Xu, Y. Guo, D. Yu, G. Guo, Y. Tang and D.P. Yu, J. Mater. Res. 17 (2002) 1711.

6. X.S. Peng, G.W. Meng, J. Zhang, X.F. Wang, C.Z. Wang, X. Liu and L.D. Zhang, J. Mater. Res. 17 (2002) 1283.

7. L. Piraux, J.M. George, J.F. Despres, C. Leroy, E. Ferain, R. Legras, K. Ounadjela and A. Fert, Appl. Phys. Lett. 65 (1994) 2484 .

8. A. Blondel, J.P. Meier, B. Doudin and J.-Ph. Ansermet, Appl. Phys. Lett. 65 (1994) 3019.

9. K. Liu, K. Nagodawithana, P.C. Searson and C.L. Chien, Phys. Rev. B. 51 (1995) 7381.

10. S. Dubois, C. Marchal, J.M. Beuken, L. Piraux, J.L. Duvail, A. Fert, J.M. George and J.L. Maurice, Appl. Phys. Lett. 70 (1997) 396.

11. G.P. Heydon, S.R. Hoon, A.N. Farley, S.L. Tomlinson, M.S Valera, K. Attenborough and W. Schwarzacher, J. Phys. D: Appl. Phys. 30 (1997) 1083.

12. M. Zenger, W. Breuer, M. Zölfl, R. Pulwey, J. Raabe and D. Weiss, IEEE Trans. Magn. 37 (2001) 2094.

13. D. Routkevitch, T. Bigioni, M. Moskovits and J.M. Xu, J. Phys. Chem. 100 (1996) 14037.

14. F. Li and R.M. Metzger, J. Appl. Phys. 81 (1997) 3806.

15. H. Zeng, M. Zheng, R. Skomski, D.J. Sellmyer, Y. Liu, L. Menon and S. Bandyopadhyay, J. Appl. Phys. 87 (2000) 4718.

16. Y. Peng, H.L. Zhang, S.L. Pan and H.L. Li, J. Appl. Phys. 87 (2000) 7405.

17. P. Forrer, F. Schlottig, H. Siegenthaler and M. Textor, J. Appl. Electrochem. 30 (2000) 533.

18. A.J. Yin, J. Li, W. Jian, A.J. Bennett and J.M. Xu, Appl. Phys. Lett. 79 (2001) 1039.

19. A. Jagminas, J. Appl. Electrochem. 32 (2002) 1201.
20. H. Masuda and K. Fukuda, Science. 268 (1995) 1466.

21. H. Masuda, H. Yamada, M. Satoh, H. Asoh, M. Nakao and T. Tamamura, WGEKHGH. Appl. Phys. Lett. 71 (1997) 2770.

22. O. Jessensky, F. Müller and U. Gösele, Appl. Phys. Lett. 72 (1998) 1173.

23. J.A. González, V. López, A. Bautista, E. Otero and X.R. Nóvoa, J. Appl. Electrochem. 29 (1999) 229.

24. A. Tayaoka, E. Tayaoka and J. Yamasaki, J. Appl. Phys. 79 (1996) 6016.

25. K. Nielsch, F. Müller, A.P. Li and U. Gösele, Adv. Mater. 12 (2000) 582.

26. T. Ohgai, X. Hoffer, L. Gravier and J.-Ph. Ansermet, J. Appl. Electrochem. 34 (2004) 1007.

27. J.E. Wegrowe, S.E. Gilbert, D. Kelly, B. Doudin and J.-Ph. Ansermet, IEEE Trans. Magn. 34 (1998) 903.

28. M.S. Martin-Gonzalez, A.L. Prieto, R. Gronsky, T. Sands and A.M. Stacy, J. Electrochem. Soc. 149 (2002) C546.

29. M. Takahashi, Y. Muramatsu, M. Watanabe, K. Wakita, T. Miyuki and S. Ikeda, J. Electrochem. Soc. 149 (2002) C311.

30. S.I. Hsiu and I.W. Sun, J. Appl. Electrochem. 34 (2004) 1057.

31. F.A. Kröger, J. Electrochem. Soc. 125 (1978) 2028.

32. K. Sridharan and K. Sheppard, J. Appl. Electrochem. 27 (1997) 1198.

33. N. Zech, E.J. Podlaha and D. Landolt, J. Appl. Electrochem. 28 (1998) 1251.

34. H. Dahms and I.M. Croll, J. Electrochem. Soc. 112 (1965) 771.

35. G. Nimtz, in O. Madelung (Ed.), Physics of II-VI and I-VII Compounds, Semimagnetic Semiconductors, Landolt-Börnstein, New Series, Group 3, Vol. 17b (Springer-Verlag, Berlin, 1982), p. 225 .

36. P. Gross and W. Richter, in O. Madelung (Ed.), Physics on NonTetrahedrally Bonded Elements and Binary Compounds, LandoltBörnstein, New Series, Group 3, Vol.17e (Springer-Verlag, Berlin, 1983), p. $106 .$.

37. A.I. Kolyubakin, V.E. Antonov, O.I. Barkalov, A.F. Gurov and A.I. Harkunov, J. Non-Cryst. Solids. 289 (2001) 30.

38. M.A. Majeed Khan, M. Zulfequar and M. Husain, J. Mater. Sci. 38 (2003) 549.

39. N.F. Mott, Phil. Mag. 22 (1970) 7. 